\title{
Quality of Life Measurement Clarifies the Cost- Effectiveness of Helicobacter pylori Eradication in Peptic Ulcer Disease and Uninvestigated Dyspepsia
}

Peter W. Groeneveld, M.D., Tracy A. Lieu, M.D., M.P.H., A. Mark Fendrick, M.D., Leo B. Hurley, M.P.H., Lynn M. Ackerson, Ph.D., Theodore R. Levin, M.D., and James E. Allison, M.D.

Department of Veterans Affairs Medical Center and University of California, San Francisco, San Francisco, and Center for Health Policy, Stanford University, Stanford, California; Department of Ambulatory Care and Prevention, Harvard Pilgrim Health Care and Harvard Medical School, Boston, Massachusetts; Division of General Medicine, University of Michigan, Ann Arbor, Michigan; Division of Research, Kaiser Permanente Medical Care Program (Northern California Region), Oakland; Department of Gastroenterology, Kaiser Permanente Medical Center, Walnut Creek; Division of Gastroenterology, San Francisco General Hospital, San Francisco; and Northern California Institute for Research and Education, San Francisco, California

OBJECTIVES: Previous economic studies of Helicobacter pylori eradication in dyspepsia and peptic ulcer disease have not measured quality of life using utilities (preference probabilities), which are needed to compare the cost-effectiveness of such treatment to other health care interventions. The goals of this study were to measure quality of life in patients with dyspepsia or peptic ulcer and apply these measurements to published models of disease management to determine cost-effectiveness in dollars per quality-adjusted life year (QALY) gained.

METHODS: Utilities for dyspepsia and peptic ulcer disease were measured in adult patients $(n=73)$ on chronic acid suppression for peptic ulcer or ulcer-like dyspepsia. Median utility values were applied to the results of published costeffectiveness analyses and a previously validated dyspepsia model. Cost-utility ratios for early $H$. pylori eradication in uninvestigated dyspepsia and peptic ulcer disease were then computed.

RESULTS: The total disutility, or lost quality of life, for an ulcer was 0.11 QALY, of which 0.09 QALY was attributed to dyspeptic symptoms. After these results were incorporated into published studies, cost-utility ratios for ulcer treatment varied from $\$ 3,100$ to $\$ 12,500$ per QALY gained, whereas estimates for uninvestigated dyspepsia management ranged from $\$ 26,800$ to $\$ 59,400$ per QALY. Sensitivity analyses indicated a range of $\$ 1,300$ to $\$ 27,300$ per QALY for management of duodenal ulcer and $\$ 15,000$ to $\$ 129,700$ per QALY for dyspepsia.

This work was conducted at the Division of Research, Kaiser Permanente Medical Care Program, Oakland, CA; University of California, San Francisco; and VA Medical Center, San Francisco, CA.
CONCLUSIONS: Strategies that emphasize early H. pylori eradication were cost-effective for patients with peptic ulcer and possibly cost-effective for patients with uninvestigated dyspepsia, relative to other medical interventions. Dyspeptic symptoms cause significant disutility that should be incorporated in future cost-effectiveness analyses of treatment strategies. (Am J Gastroenterol 2001;96:338-347. (c) 2001 by Am. Coll. of Gastroenterology)

\section{INTRODUCTION}

The discovery of the role of Helicobacter pylori has greatly altered the diagnosis and treatment of patients with dyspepsia and peptic ulcer disease. Several cost-effectiveness analyses (1-23) have evaluated the cost and quality tradeoffs of treating patients with these conditions by modeling the rate of $H$. pylori eradication, disease recurrence, need for endoscopy, and associated resource use. Cost-effectiveness in these studies was expressed in terms such as dollars per ulcer cured or prevented, cost per patient treated, or percentage of time free from ulcer symptoms. As health benefits in these studies were reported in terms of ulcer disease only, it was not possible to compare the cost-effectiveness of $H$. pylori eradication with the treatment of other medical conditions.

The quality-adjusted life-year (QALY) is a standard measure of health benefit recommended by the national Panel on Cost-Effectiveness in Health and Medicine (1996) (24-26). Its incorporation into economic analyses of the treatment of uninvestigated dyspepsia and peptic ulcer would enable policymakers to judge the cost-effectiveness of such strategies compared to other medical interventions. However, better information is needed about patient preferences (utilities), which are used to calculate QALYs. The only pub- 
lished cost-effectiveness analysis to use utilities did not measure them directly but estimated them from Index of Well-Being scores, and the estimated ulcer disutility of 0.021 QALY did not account for lost utility due to dyspeptic symptoms (6).

In this study, we interviewed patients with ulcer-like dyspeptic symptoms to assess their preferences (utilities) regarding ulcer-related health states and other outcomes associated with the conditions. We then identified published economic analyses of peptic ulcer disease and uninvestigated dyspepsia, and used the empirically derived utilities to calculate the cost-effectiveness of various management strategies. We also updated our previous cost-effectiveness model to reflect improved estimates of $H$. pylori prevalence, test performance, treatment efficacy, and clinical costs to estimate the current cost per QALY gained for the treatment of uninvestigated dyspepsia.

\section{MATERIALS AND METHODS}

\section{Setting}

Patients were members of a large Northern California health maintenance organization who were participating in the STOMACH (Study of Management and Costs of Helicobacter pylori Infection) investigation of the care of patients on long-term acid suppressive therapy. The Kaiser Foundation Research Institute's Review Board for the protection of human subjects approved the study. Subjects were identified through pharmacy record review. Patients who had received H2-receptor antagonists or proton pump inhibitors for at least three 30-day periods during the most recent 12 months and who had diagnoses of duodenal ulcer, gastric ulcer, peptic ulcer disease, or gastritis (according to the International Classification of Diseases, ninth revision, codes) were contacted by mail. From the respondents to this mailing, enrollees were selected if medical chart review confirmed a physician diagnosis of peptic ulcer disease documented by endoscopy or x-ray, or dyspeptic symptoms defined as fasting or postprandial epigastric pain relieved with antacid, food, H2-receptor antagonists, or proton pump inhibitors.

Subjects with classic gastroesophageal reflux disease symptoms (substernal burning and/or regurgitation, worse after meals or when supine and relieved with acid suppressive medications) were excluded unless they also had documented peptic ulcer disease or dyspeptic symptoms. Further exclusion criteria were as follows: age $<18$ yr or $>80$ yr; upper GI tract malignancy; contraindication to endoscopy; pregnancy; allergy to amoxicillin, clarithromycin, metronidazole, or omeprazole; previous $H$. pylori treatment; or chronic use of nonsteroidal anti-inflammatory drugs (defined as six or more doses per week). Of the 650 enrollees in the STOMACH study, a convenience sample (patients who enrolled at times that utility interviewers were available, $\mathrm{n}=73$ ) was invited to participate in utility assessment interviews.

\section{Utility Elicitation}

We selected the time trade-off method for utility elicitation instead of the standard gamble because the time trade-off is more comprehensible to many patients $(27,28)$. Patients were interviewed by one of two interviewers trained in utility assessment elicitation techniques. The interviewer began by presenting the patient with four cards describing perfect health, mild dyspepsia, moderate dyspepsia, and severe dyspepsia (see Appendix). Patients were asked which scenario best described their current health state. Patients were then provided with an estimate of their remaining life expectancy based on their current age. They were subsequently presented with a visual metric device to facilitate comparisons of fractional values of remaining life expectancy. The interviewer set the metric to an initial value of $5 \%$, and asked the patient if he/she would prefer to live his/her entire remaining life expectancy (e.g., $40 \mathrm{yr}$ ) with mild dyspepsia (as described), or $95 \%$ of his/her remaining life (e.g., $38 \mathrm{yr}$ ) in "perfect health." The metric was adjusted and the question was repeated, until a point of indifference was determined; this value was recorded as the time tradeoff for mild dyspepsia. This process was repeated for moderate and severe dyspeptic symptoms.

Next, the patients were asked about four ulcer-related scenarios. Brief descriptions of the symptoms, events, and procedures involved in having an ulcer-related complication were given. Patients were then asked how much of their remaining life expectancy they would trade to avoid the scenario using a similar technique as described previously. Patients were also asked to give time trade-off values for a combination of potential adverse effects of two commonly used $H$. pylori treatment regimens (omeprazole/amoxicillin/ clarithromycin and omeprazole/clarithromycin/metronidazole) (Appendix).

\section{Utility Calculation}

Each patient's time values elicited from the time trade-off interviews were discounted at a rate of $3 \%$ (24). Utility coefficients for dyspeptic health states were calculated by dividing each patient's "perfect health" life expectancy equivalent by the patient's estimated life expectancy (29). The value of health events such as perforation or GI bleed was determined by calculating the number of QALYs a patient would exchange to avoid one adverse event. The median values for the time trade-off utility of the various levels of dyspepsia as well as the median values of disutility for ulcer-related complications were used in cost-effectiveness modeling.

\section{Statistical Analyses}

Utilities for mild, moderate and severe dyspepsia were compared using the Mann-Whitney rank sum test for nonnormally distributed data. Cohort-wide estimates for the time trade-off value of mild, moderate and severe dyspepsia were compared using the Friedman test for matched groups, as the data were not normally distributed. The Friedman test 
Table 1. Results of Cost-Effectiveness Analyses Using Empirically-Derived Utility Data

\begin{tabular}{|c|c|c|c|}
\hline Author (Year) ${ }^{\text {Ref. }}$ & Population/disease & Comparison & Primary Result \\
\hline O’Brien $(1995)^{13}$ & Diagnosed duodenal ulcer & $\begin{array}{l}\text { Empiric anti-secretory/antimicrobial } \\
\text { therapy compared to no therapy }\end{array}$ & $\begin{array}{l}\$ 383 \text { (Canadian) per recurrent } \\
\text { ulcer prevented }\end{array}$ \\
\hline Fendrick $(1995)^{7}$ & Uninvestigated dyspepsia & $\begin{array}{l}\text { Empiric anti-secretory/antimicrobial } \\
\text { therapy compared to no therapy }\end{array}$ & $\begin{array}{l}\$ 4155 \text { per additional ulcer } \\
\text { cured }\end{array}$ \\
\hline Jossson $(1996)^{11}$ & Diagnosed duodenal ulcer & $\begin{array}{l}\text { Empiric anti-secretory/antimicrobial } \\
\text { therapy compared to no therapy }\end{array}$ & $\begin{array}{l}7420 \text { krona per ulcer relapse } \\
\text { prevented }\end{array}$ \\
\hline Ebell $(1997)^{6}$ & Uninvestigated dyspepsia & $\begin{array}{l}\text { Empiric anti-secretory/antimicrobial } \\
\text { therapy compared to no therapy }\end{array}$ & $\begin{array}{l}\$ 5781 \text { per additional ulcer } \\
\text { cured }\end{array}$ \\
\hline Duggan $(1998)^{5}$ & Diagnosed duodenal ulcer & $\begin{array}{l}\text { Treating patients who test positive } \\
\text { for } H \text {. pylori compared to no } \\
\text { therapy }\end{array}$ & $\begin{array}{l}240 \text { pounds per additional } \\
\text { ulcer prevented }\end{array}$ \\
\hline $\begin{array}{l}2000 \text { Dyspepsia } \\
\text { "Test and Treat" strategy }\end{array}$ & Uninvestigated dyspepsia & $\begin{array}{c}\text { Testing for } H . \text { pylori and treating if } \\
\text { positive, compared to no therapy }\end{array}$ & N/A \\
\hline Author (Year) & \multicolumn{2}{|c|}{$\begin{array}{l}\text { Result Converted to Dollar/QALY } \\
\text { Using Time Trade-off Utilities }\end{array}$} & $\begin{array}{c}\text { Range with Varied } \\
\text { Utility Estimates }\end{array}$ \\
\hline O’Brien (1995) & & $\$ 3,100 / \mathrm{QALY}$ & $\$ 1,800-\$ 6,900$ \\
\hline Fendrick (1995) & & $\$ 45,500 / \mathrm{QALY}$ & $\$ 25,500-\$ 99,400$ \\
\hline Jonsson (1996) & & $\$ 12,500 / \mathrm{QALY}$ & $\$ 7,000-\$ 27,300$ \\
\hline Ebell (1997) & & $\$ 59,400 / \mathrm{QALY}$ & $\$ 33,200-\$ 129,700$ \\
\hline Duggan (1998) & & $\$ 4,700 / \mathrm{QALY}$ & $\$ 1,300-\$ 20,500$ \\
\hline 2000 Dyspepsia & & $\$ 26,800 / \mathrm{QALY}$ & $\$ 15,000-\$ 58,600$ \\
\hline
\end{tabular}

Currency conversion: 1995) 1 Canadian dollar $=\$ 0.75$ US; 1996) 1 Swedish krona $=\$ 0.1504$ US; 1998) 1 British pound $=\$ 1.631$ US (61). All values then normalized to year 2000 \$US.

was also employed to compare the disutilities of ulcerrelated complications. The Bonferroni correction was used to adjust for the effect of multiple comparisons. Confidence intervals were estimated using a binomial approximation. All statistical analyses were performed using Stata 5.0 (Stata, College Station, TX).

\section{Cost-Effectiveness Analyses}

Using the MEDLINE database for the years 1966-2000 as well as reference lists from published articles, we identified 16 candidate economic analyses that examined the costeffectiveness of various strategies for treating uninvestigated dyspepsia or peptic ulcer disease. We confined our search to articles that compared strategies for the treatment of $H$. pylori and that produced an explicit cost-effectiveness ratio or cost-benefit monetary value. As our utility calculation yielded the QALY value of a clinical event, we further limited our search to studies that published incremental cost-effectiveness ratios in terms of cost per ulcer-related clinical event (Table 1). This criterion eliminated five studies that stated the costs of treatment in terms of "average cost per patient" $(10,14,16,17,22)$ and three studies that computed empirical cost savings of one strategy compared with another strategy $(12,19,20)$. Finally, three studies listing effectiveness in terms of "average time without ulcer" were also excluded, as our utilities did not measure disutility from ulcer as time spent in the "ulcer" health state $(2,8,18)$. The five cost-effectiveness analyses we identified as appropriate for conversion each took a payer perspective for cost accounting. Finally, we abstracted the "dominant" (least costly and most effective) strategy from each study (Table 1).

\section{Conversion of Cost-Effectiveness Ratios}

To convert the effectiveness of an "additional ulcer prevented" to QALYs gained we estimated the average disutility of an ulcer. We assumed that patients who develop an ulcer have a $5 \%$ annual rate of complication (i.e., requiring hospital admission/invasive procedures) $(30,31)$. We estimated that $92 \%$ of such patients would be admitted with GI bleeding, $6 \%$ would have a perforation, and $2 \%$ would die (31-33). As published data on ulcer complication rates do not differentiate between index and recurrent ulcers, we assumed that all ulcers would have the same rate of complications and death. By multiplying these frequencies by the empirically measured disutilities for each event, an overall average disutility in terms of QALYs lost per ulcer was determined. We then tested our assumptions by performing sensitivity analyses that varied the rate of ulcer complication, bleeding, perforation, and death over ranges obtained from the medical literature.

To approximate the average number of days of dyspeptic symptoms expected per ulcer occurrence, we used published data on the health impact of peptic ulcer that measured the average number of "restricted activity days" (analogous to our "moderate dyspepsia" category) and "bed days" (similar to our "severe dyspepsia" category) per year in 4580 patients with self-reported ulcers (30). This estimated that each ulcer would cause, on average, 12 days of severe dyspeptic symptoms and 23 days of moderate symptoms. The total 
disutility of an ulcer was therefore the sum of the eventrelated disutility (i.e., bleeding, obstruction) plus the disutility of 35 days of dyspeptic symptoms.

To convert "additional cases of H. pylori eradicated" to QALYs, we used published estimates of the lifetime incidence of ulcer in $H$. pylori infected individuals $(30,31)$, which suggested that for $H$. pylori eradication the average number-needed-to-treat to prevent one clinically apparent ulcer is 10 (range, five to 20). In converting cost-effectiveness ratios from published models that used time horizons $>1 \mathrm{yr}$, we discounted health benefits and costs at $3 \%$ annually $(5,11,24)$. The rate of ulcer complications was assumed not to vary over the lifetime of the patient. Non-US currencies were converted into the appropriate US dollar amounts using exchange rates appropriate for the year of publication. All converted costs were inflated to year 2000 dollars using the consumer price index for medical services.

\section{Updated Dyspepsia Analysis}

Several investigations since 1997 (the date of the most recent dyspepsia analysis included in our study) have enhanced understanding of ulcer and H. pylori epidemiology, $H$. pylori test characteristics, treatment efficacy, and ulcer recurrence rates (34-41). We updated our dyspepsia treatment model to reflect this new evidence; we also substituted year 2000 cost data to estimate the current cost-utility ratio for the management of dyspepsia. Details of the design and assumptions of this model, which took the "payer perspective" in measuring healthcare costs, have been published elsewhere (7). Several recent clinical practice guidelines have recommended $H$. pylori testing rather than empiric therapy as initial management for dyspepsia (34, 42-45), reflecting decreases in the cost of initial testing combined with better estimates of $H$. pylori prevalence. Thus, a strategy of "test and treat" was employed for the management of dyspeptic patients in our updated model, as this strategy was determined to be the most cost-effective option. Our baseline assumptions included a $H$. pylori prevalence of $33 \%$ and an ulcer prevalence of $20 \%$ (80\% of these ulcers were ascribed to H. pylori) ${ }^{14} \mathrm{C}$ urea breath testing was used as an initial screening test in our model, with positive tests resulting in treatment with $H$. pylori eradication therapy. Patients who tested negative for $H$. pylori were given an initial trial of H2-receptor antagonists. Cost estimates included $\$ 600$ per endoscopy, $\$ 150$ for urea breath testing, and $\$ 25$ for rapid urease testing at endoscopy, $\$ 190$ for $H$. pylori eradication therapy, and $\$ 45$ per month for maintenance antisecretory therapy. The cost per ulcer cured was calculated, and this value was converted to a cost-utility ratio using our derived QALY value of a prevented ulcer.

\section{RESULTS}

The 73 patients with peptic ulcer disease or uninvestigated dyspepsia included patients with a wide range of symptoms (Table 2). The proportions of African American, Asian,
Table 2. Characteristics of 73 Patients on Chronic AcidSuppression Therapy for Peptic Ulcer or Dyspepsia

\begin{tabular}{lc}
\hline \multicolumn{1}{c}{ Characteristic } & Number $(\%)$ or \\
& Mean \pm SD (Range) \\
\hline Average age, yr & $57 \pm 13(20-76)$ \\
Female sex & $43(59 \%)$ \\
Race & \\
Caucasian & $46(63 \%)$ \\
African American & $12(16 \%)$ \\
Asian & $4(6 \%)$ \\
Latin American & $4(6 \%)$ \\
Other & $7(10 \%)$ \\
Current disease severity* & \\
"Perfect health" & $1(1 \%)$ \\
Mild symptoms & $18(25 \%)$ \\
Moderate symptoms & $29(40 \%)$ \\
Severe symptoms & $25(34 \%)$ \\
History of ulcer-related complications & $7(10 \%)$ \\
Obstruction without surgery & $4(5 \%)$ \\
Obstruction with surgery & $11(15 \%)$ \\
Gastrointestinal bleeding & $2(3 \%)$ \\
Perforated ulcer & $50(68 \%)$ \\
None of the above & \\
Current acid-suppression medication & $60(82 \%)$ \\
H2-receptor antagonists $\dagger$ & $15(21 \%)$ \\
Proton-pump inhibitors & $1(1 \%)$ \\
Noneł & $3.4 \pm 1.3(1-8)$ \\
Duration of acid-suppression therapy, yr & \\
Highest educational level attained & $4(5 \%)$ \\
11th grade or less & $14(19 \%)$ \\
High school graduate or equivalent & $35(48 \%)$ \\
Some college or technical school & $15(21 \%)$ \\
College graduate & $5(7 \%)$ \\
Graduate degree & \\
Annual household income $\$$ & $4(6 \%)$ \\
Under \$15,000 & $25(40 \%)$ \\
\$15,001-\$35,000 & $14(23 \%)$ \\
\$35,001-\$50,000 & $12(19 \%)$ \\
\$50,001-\$80,000 & \\
Greater than \$80,000 & \\
\hline
\end{tabular}

\footnotetext{
* Refer to Appendix.

$\dagger$ Three patients reported concurrent H2-receptor antagonist and proton pump inhibitor use.

$\ddagger$ One patient reported recent use of H2-receptor antagonists (in past 12 months) but denied current use.

$\S$ Eleven patients refused to provide annual income information.
}

Latin American, and Caucasian patients were similar to the corresponding proportions of adults in northern California (46). Most patients were taking $\mathrm{H} 2$-receptor antagonists regularly, and some had been taking acid-suppression therapy for up to $8 \mathrm{yr}$. Fewer than half of the patients had experienced a complication from a previous ulcer.

\section{Dyspepsia-Related Utilities}

Patients with mild and moderate dyspepsia assigned similar utility scores to their health states. Patients with severe dyspepsia reported a lower median quality-of-life time trade-off score (Table 3), although this difference did not reach statistical significance ( $p=0.06$ ) compared with mild and moderate dyspeptic patients. Among the entire cohort the median score for severe dyspepsia (0.87) was significantly less than the score for mild or moderate dyspepsia 
Table 3. Time Trade-Off Utilities for Dyspepsia Derived From 73 Patients With Chronic Dyspeptic Symptoms

\begin{tabular}{|c|c|c|c|c|c|c|}
\hline \multirow[b]{2}{*}{$\begin{array}{l}\text { Symptom } \\
\text { Level }\end{array}$} & \multicolumn{2}{|c|}{ All Patients } & \multicolumn{2}{|c|}{$\begin{array}{l}\text { Patients With the } \\
\text { Given Symptom Level }\end{array}$} & \multicolumn{2}{|c|}{$\begin{array}{l}\text { Patients Without the } \\
\text { Given Symptom Level }\end{array}$} \\
\hline & $\mathrm{n}$ & $\begin{array}{l}\text { Median Utility } \\
\quad(95 \% \mathrm{CI})\end{array}$ & $\mathrm{n}$ & $\begin{array}{l}\text { Median Utility } \\
\quad(95 \% \text { CI })\end{array}$ & $\mathrm{n}$ & $\begin{array}{l}\text { Median Utility } \\
\quad(95 \% \mathrm{CI})\end{array}$ \\
\hline None & 73 & $\mathrm{n} / \mathrm{a}$ & 1 & 1 & 72 & $\mathrm{n} / \mathrm{a}$ \\
\hline Mild & 73 & $0.92(0.91-0.96)$ & 18 & $0.91(0.89-0.96)$ & 55 & $0.93(0.90-0.96)$ \\
\hline Moderate & 73 & $0.91(0.90-0.94)$ & 29 & $0.90(0.87-0.96)$ & 44 & $0.91(0.89-0.94)$ \\
\hline Severe & 73 & $0.87(0.81-0.90)$ & 25 & $0.87(0.79-0.94)$ & 48 & $0.87(0.73-0.89)$ \\
\hline
\end{tabular}

(0.92, $p<0.0001)$. No significant differences were noted between the utility scores for mild, moderate, and severe dyspepsia assigned by patients actually in that particular health state compared to the utility scores assigned by patients who were not in the health state. Additionally, no statistical difference was found between the utility scores assigned to mild, moderate, and severe dyspepsia when the respondents were stratified by age or by the presence of a diagnostically confirmed ulcer (Table 4).

\section{Event-Related Disutilities}

The distributions for event-related disutilities were highly skewed; $32 \%$ of the patients indicated that they would be unwilling to trade any of their remaining life expectancy to avoid an ulcer-related complication. Among the remaining patients, the range for disutility of gastric outlet obstruction was 0.01-3.56 QALYs, for GI bleeding was 0.01-12.41 QALYs, for obstruction requiring surgery was 0.01-17.27 QALYs, and for perforation was 0.01-23.81 QALYs (Table $5)$. The distributions of these values for all participants and for the subset who reported nonzero time trade-off values were significantly different when compared statistically $(p<0.0001)$. There was no significant difference noted between patient preferences for the two $H$. pylori antibiotic courses.

Using these utility data and the assumptions regarding the frequency of adverse ulcer-related events, we estimated that an ulcer had a disutility of 0.11 QALY, of which approximately 0.09 was attributable to dyspeptic symptoms, whereas 0.02 was lost from complications including death.
These results did not vary when derived only from the subset of patients with a diagnostically confirmed ulcer or the subset with uninvestigated dyspepsia. By varying our assumptions on the epidemiology of ulcer-related complications and death to the highest estimates published in the literature combined with using the maximal $95 \%$ confidence boundaries for disutilities, we estimated a maximal disutility per ulcer of 0.19 QALY. Using the lowest published estimates for the rates of ulcer-related complications combined with the minimal $95 \%$ confidence estimates for adverseevent and dyspepsia-related disutilties yielded a minimum estimate for disutility per ulcer of 0.05 QALY.

\section{Application of Utilities to Published Cost-Effectiveness Analyses}

Of the five studies that we examined, three dealt with the treatment of peptic/duodenal ulcer and two focused on uninvestigated dyspepsia. Using our "base case" estimate of the disutility of an ulcer, we determined that the initial treatment of duodenal ulcer patients with empiric antibiotic/ antisecretory therapy had a cost-utility ratio between $\$ 3,100$ and \$12,500 dollars per QALY gained (Table 1). Empiric treatment of uninvestigated dyspeptic patients with $H$. pylori eradication therapy cost between $\$ 44,700$ and $\$ 58,300$ per QALY gained. The range of cost-effectiveness ratios for peptic ulcer disease management was less than $\$ 50,000$ through a wide range of varying assumptions, although dyspepsia treatment exceeded $\$ 100,000$ per QALY gained under some conditions (Table 1) (47).

Table 4. Time Trade-Off Utilities for Dyspepsia Stratified by Age and Diagnosis

\begin{tabular}{|c|c|c|c|c|}
\hline & $\mathrm{n}$ & $\begin{array}{c}\text { Mild } \\
\text { Dyspepsia } \\
\text { Median Utility } \\
(95 \% \mathrm{CI})\end{array}$ & $\begin{array}{c}\text { Moderate Dyspepsia } \\
\text { Median Utility } \\
(95 \% \text { CI })\end{array}$ & $\begin{array}{l}\text { Severe Dyspepsia } \\
\text { Median Utility } \\
(95 \% \mathrm{CI})\end{array}$ \\
\hline \multicolumn{5}{|l|}{ Quartile (age) } \\
\hline Youngest (21-47) & 18 & $0.91(0.89-0.96)$ & $0.92(0.89-0.97)$ & $0.88(0.59-0.91)$ \\
\hline Second $(47-59)$ & 18 & $0.95(0.92-0.96)$ & $0.93(0.89-0.96)$ & $0.90(0.74-0.94)$ \\
\hline Third $(59-65)$ & 18 & $0.95(0.87-0.96)$ & $0.91(0.87-0.95)$ & $0.87(0.79-0.95)$ \\
\hline Oldest $(>65)$ & 19 & $0.91(0.87-0.96)$ & $0.91(0.87-0.96)$ & $0.78(0.62-0.88)$ \\
\hline$p$ Value for difference between quartiles & & 0.23 & 0.54 & 0.26 \\
\hline Diagnosis upon study entry & $\mathrm{n}$ & & & \\
\hline Confirmed ulcer* & 10 & $0.89(0.81-0.96)$ & $0.93(0.82-0.96)$ & $0.88(0.54-0.95)$ \\
\hline Uninvestigated dyspepsia & 63 & $0.93(0.91-0.96)$ & $0.91(0.90-0.94)$ & $0.87(0.79-0.91)$ \\
\hline$p$ Value for difference between groups & & 0.21 & 0.78 & 0.80 \\
\hline
\end{tabular}

* Confirmed by endoscopy or barium swallow before enrollment in the study. 
Table 5. Disutilities of Ulcer-Related Complications and Helicobacter pylori Treatment (QALYs)

\begin{tabular}{lcl}
\hline \multicolumn{1}{c}{ Complication } & $\begin{array}{c}\text { Median Disutility } \\
(95 \% \mathrm{CI})\end{array}$ & Range \\
\hline Obstruction without operation & $0(0-0.01)$ & $0-3.6$ \\
Gastrointestinal bleed & $0.01(0-0.01)$ & $0-12.4$ \\
$\begin{array}{l}\text { Obstruction with operation } \\
\text { Perforation }\end{array}$ & $0.01(0-0.05)$ & $0-17.3$ \\
$\begin{array}{l}\text { H. pylori treatment } \\
\text { Amoxicillin/clarithromycin/ } \\
\quad \text { omeprazole }\end{array}$ & $0.01(0-0.1)$ & $0-23.8$ \\
$\begin{array}{l}\text { Metronidazole/clarithromycin/ } \\
\text { omeprazole }\end{array}$ & $0(0-0.0001)$ & $0-0.27$ \\
\hline
\end{tabular}

\section{Application of Utilities to Updated Dyspepsia Analysis}

Using the revised model for the "test and treat" strategy using 2000 clinical and cost data, we calculated a value of $\$ 2788$ per ulcer cured for a strategy of managing uninvestigated dyspepsia that used initial $H$. pylori testing proceeding to eradication therapy if testing was positive. This was equivalent to a cost-utility ratio of $\$ 26,800$ per QALY gained. Sensitivity analysis suggested a "low cost" boundary of $\$ 15,000$ and a "high cost" boundary of $\$ 58,600$ per QALY for this model.

\section{DISCUSSION}

\section{Major Findings}

Our results suggest that interventions directed at $H$. pylori are cost-effective in patients with peptic ulcer disease and potentially cost-effective in those with uninvestigated dyspepsia, compared with other medical interventions (Table 6). Time trade-off utilities for dyspeptic symptom health states and ulcer-related health events were easily measured and were ordered by degree of severity, raising confidence that patients can provide valid measures of utilities. Based on the utilities of the patients we interviewed, $>80 \%$ of the value of ulcer prevention can be attributed to symptom reduction; the remainder can be ascribed to reducing the risk of death or ulcer-related complications such as perforation or bleeding.

\section{Comparisons With Other Studies}

Previous studies of health-related quality of life for patients with dyspepsia, peptic ulcer, or gastroesophageal reflux disease have used rating-scale instruments such as the GI Symptom Rating Scale. Such indices have been more thoroughly evaluated than utility assessment in patients with upper GI syndromes (48-50), but they cannot be reliably converted into quality-adjusted life years $(28,51-54)$. Utilities are uniquely useful because they enable health benefits to be measured in QALYs, which allow comparisons with other health care interventions.

We elicited utilities in patient interviews using the widely accepted time trade-off method (28). Only one prior analysis of the cost-effectiveness of treating dyspeptic patients has used QALYs. Ebell et al. designed a Markov model comparing seven different strategies for empiric management of dyspeptic patients (6). Utility measurements were estimated from Index of Well-Being scores. Ebell et al. assumed the disutility of inpatient treatment of a complicated ulcer was 0.021 , which is similar to the values we obtained from empiric measurements. However, the model of Ebell et al. did not incorporate dyspepsia-related disutility, which was the largest component of overall ulcer-related disutility in our study.

Not surprisingly, our findings confirm the cost-effectiveness of empiric treatment of $H$. pylori at the time of initial diagnosis of duodenal ulcer $(5,11,13)$. Incorporating our study's empiric utilities in the analyses of Ebell et al. and Fendrick et al. $(6,7)$ suggests that strategies focused on the early treatment of $H$. pylori in the management of uninvestigated dyspepsia are possibly cost-effective, but less so than the eradication of $H$. pylori in peptic ulcer disease. This is due to $H$. pylori eradication being far more effective in the treatment of duodenal ulcer disease $(80-90 \%$ cure rate with eradication therapy at $1 \mathrm{yr})(55,56)$ compared with nonulcer dyspepsia $(0-22 \%$ cure rate with eradication therapy at $1 \mathrm{yr})$ $(37,57,58)$. Indeed, it is possible that the only dyspeptic patients who benefit from $H$. pylori eradication are those with actual ulcers causing their dyspepsia.

The question of whether $H$. pylori eradication is an effective component of managing uninvestigated dyspepsia is

Table 6. Comparison of Cost Per QALY Values of Common Medical Interventions

\begin{tabular}{|c|c|}
\hline Intervention & Reference Case Cost/Utility Ratio \\
\hline $\begin{array}{l}\text { Instituting dialysis and continuing aggressive therapy in hospitalized adults with very } \\
\text { poor prognoses }\end{array}$ & $\$ 298,200 / \mathrm{QALY}{ }^{62}$ \\
\hline $\begin{array}{l}\text { Endoscopic surveillance every } 5 \mathrm{yr} \text { in patients with Barrett's esophagus versus no } \\
\text { surveillance }\end{array}$ & $\$ 99,900 / \mathrm{QALY}{ }^{63}$ \\
\hline $\begin{array}{l}\text { Allogenic bone marrow transplant for a } 35 \text {-yr-old woman with chronic myelogenous } \\
\text { leukemia versus interferon }\end{array}$ & $\$ 54,600 / \mathrm{QALY}{ }^{64}$ \\
\hline $\begin{array}{l}\text { Proton-pump inhibitors as first line therapy for patients with mild gastroesophageal } \\
\text { reflux disease }\end{array}$ & $\$ 37,900 / \mathrm{QALY} \mathrm{Y}^{65}$ \\
\hline Primary angioplasty for acute myocardial infarction compared with thrombolysis & $\$ 13,100 / \mathrm{QALY} \mathrm{Y}^{66}$ \\
\hline Hip replacement for men with osteoarthritis aged $85 \mathrm{yr}$ compared to no therapy & $\$ 5,100 / \mathrm{QALY}^{67}$ \\
\hline Interferon $\alpha$-2B plus ribavirin for hepatitis C versus no therapy & Cost saving $^{68}$ \\
\hline
\end{tabular}

Values inflated to year 2000 dollars from publication year using the consumer price index for medical services. 
highly controversial (59). Understanding the relative economic value of $H$. pylori treatment for uninvestigated dyspepsia can lend insight into difficult decisions about appropriate management strategies. Of note, our Markov model indicated that dyspepsia management using a "test-andtreat" initial strategy was more cost-effective than the optimal management strategies published in previous economic studies of uninvestigated dyspepsia. Sensitivity analysis of our model suggested an upper cost per QALY boundary of $\$ 57,500$, which is comparable to other interventions deemed cost-effective in the United States $(47,60)$.

\section{Limitations}

Our analysis has important limitations. First, the average number of symptomatic days per ulcer was extrapolated from population data; the actual value is unknown. Our estimates could result in inappropriately high or low estimates for the QALY value of an ulcer. We addressed this by varying the inputs used in calculating the disutility of an ulcer in our sensitivity analyses to provide a reasonable estimate of the range of possible values.

Second, the ideal method of incorporating empirically measured utilities is in the design and execution of an analytic model; this was not feasible for any of the published analyses we examined. It is possible that converting the end product of an analysis (i.e., dollars per cured ulcer into dollars per QALY) may inadvertently omit some of the nuances of cost and effectiveness accounting that complex models are designed to capture.

Third, our study population may have not adequately represented "typical" patients with ulcer disease or uninvestigated dyspepsia who were the subjects of the published cost-effectiveness models. As our study comprised patients with chronic, refractory symptoms, it is possible that our patients experienced greater disutility from their symptoms and had greater concern about ulcer-related complications. We may therefore have overestimated the cost-effectiveness of uninvestigated dyspepsia and ulcer management. However, we found that our patients' assessments of the utility of mild, moderate, and severe dyspepsia were independent of current symptom level. Additionally, some cost-effectiveness analysts have argued that patients who are actually in "poor" health rate their quality of life as higher than do healthier patients asked to estimate the quality of their life if they were in "poor" health (60), thus utility ratings in our patients may have been higher than in typical patients with episodic dyspepsia or peptic ulcer. We may therefore have underestimated the cost-effectiveness of dyspepsia and ulcer management, inasmuch as patients with symptoms that are less chronic or refractory may perceive greater disutility from their symptoms and thus stand to gain greater benefits from treatment (60). Further investigation of the utility of dyspepsia in different populations is needed to address these issues.

Finally, patients with actual ulcers may experience disutility from their symptoms different from that of patients with other diagnoses (e.g., nonulcer dyspepsia). Nevertheless, our study detected no difference in utility scores between patients with confirmed ulcers and those with uninvestigated dyspepsia, suggesting any variation in symptom-related disutility among dyspeptic patients with differing diagnoses is small.

In conclusion, our analysis indicates that patients with peptic ulcer disease and ulcer-like dyspepsia assign their health states substantial disutility. Expressing the cost-effectiveness of interventions for these conditions in dollars per QALY captures their value in improving health-related quality of life and highlights opportunities for clinical care to prevent lost quality of life. Cost per QALY ratios also provide a way to directly compare ulcer and uninvestigated dyspepsia intervention cost-effectiveness with other healthcare interventions. The eradication of $H$. pylori is relatively cost-effective for patients with peptic ulcer disease; however, the cost-effectiveness of $H$. pylori eradication as an initial step in the management of all dyspeptic patients is less certain. Further economic, clinical, and epidemiological studies are necessary to ascertain better the cost-effectiveness of early $H$. pylori eradication in these patients.

\section{ACKNOWLEDGMENTS}

This study was supported by a grant from AstraZeneca L.P. The authors gratefully acknowledge the contributions of Dionne Libran, administrative coordinator of the STOMACH study, as well as Julie Chu and Gloria Samaniego, who conducted the utility assessment interviews. They also thank Warren S. Browner MD, M.P.H. (Veterans Affairs Medical Center, San Francisco) and Alan S. Go, M.D. (Division of Research, Kaiser Permanente Medical Care Program, Oakland, CA) for their assistance with the development of the manuscript.

Reprint requests and correspondence: Peter W. Groeneveld, M.D., Center for Health Policy, 179 Encina Commons, MC 6019, Stanford, CA 94305-6019.

Received June 14, 2000; accepted Sep. 25, 2000.

\section{REFERENCES}

1. Craig AM, Davey P, Malek M, et al. Decision analysis of Helicobacter pylori eradication therapy using omeprazole with either clarithromycin or amoxicillin. Pharmacoeconomics 1996;10:79-92.

2. Briggs AH, Sculpher MJ, Logan RP, et al. Cost effectiveness of screening for and eradication of Helicobacter pylori in management of dyspeptic patients under 45 years of age. $\mathrm{Br}$ Med J 1996;312:1321-5.

3. Cromwell DM, Pasricha PJ. Endoscopy or empirical treatment for peptic ulcer disease: Decisions, decisions. Gastroenterology 1996;110:1314-6.

4. Deltenre M, Ilunga KO. Helicobacter pylori eradication in duodenal ulcer disease is cost-beneficial: A Belgian model. J Physiol Pharmacol 1997;48(suppl 4):107-13.

5. Duggan AE, Tolley K, Hawkey CJ, et al. Varying efficacy of 
Helicobacter pylori eradication regimens: Cost effectiveness study using a decision analysis model. Br Med J 1998;316: $1648-54$.

6. Ebell MH, Warbasse L, Brenner C. Evaluation of the dyspeptic patient: A cost-utility study. J Fam Pract 1997;44:545-55.

7. Fendrick AM, Chernew ME, Hirth RA, et al. Alternative management strategies for patients with suspected peptic ulcer disease. Ann Intern Med 1995;123:260-8.

8. Fendrick AM, McCort JT, Chernew ME, et al. Immediate eradication of Helicobacter pylori in patients with previously documented peptic ulcer disease: Clinical and economic effects. Am J Gastroenterol 1997;92:2017-24.

9. Habu Y, Inokuchi H, Kiyota K, et al. Economic evaluation of Helicobacter pylori eradication for the treatment of duodenal ulcer disease in Japan: A decision analysis to assess eradication strategy in comparison with a conventional strategy. J Gastroenterol Hepatol 1998;13:280-7.

10. Imperiale TF, Speroff T, Cebul RD, et al. A cost analysis of alternative treatments for duodenal ulcer. Ann Intern Med 1995;123:665-72.

11. Jonsson B. Cost-effectiveness of Helicobacter pylori eradication therapy in duodenal ulcer disease. Scand J Gastroenterol 1996;215(suppl):90-5.

12. Levin TR, Schmittdiel JA, Henning JM, et al. A cost analysis of a Helicobacter pylori eradication strategy in a large health maintenance organization. Am J Gastroenterol 1998;93: 743-7.

13. O'Brien B, Goeree R, Mohamed AH, et al. Cost-effectiveness of Helicobacter pylori eradication for the long-term management of duodenal ulcer in Canada. Arch Intern Med 1995;155: $1958-64$.

14. Ofman JJ, Etchason J, Fullerton S, et al. Management strategies for Helicobacter pylori-seropositive patients with dyspepsia: Clinical and economic consequences. Ann Intern Med 1997;126:280-91.

15. Phull PS, Ryder SD, Halliday D, et al. The economic and quality-of-life benefits of Helicobacter pylori eradication in chronic duodenal ulcer disease-A community-based study. Postgrad Med J 1995;71:413-8.

16. Powell KU, Bell GD, Bolton GH, et al. Helicobacter pylori eradication in patients with peptic ulcer disease: Clinical consequences and financial implications. Q J Med 1994;87:28390.

17. Silverstein MD, Petterson T, Talley NJ. Initial endoscopy or empirical therapy with or without testing for Helicobacter pylori for dyspepsia: A decision analysis. Gastroenterology 1996;110:72-83.

18. Sonnenberg A, Townsend WF. Costs of duodenal ulcer therapy with antibiotics. Arch Intern Med 1995;155:922-8.

19. Sonnenberg A. Cost-benefit analysis of testing for Helicobacter pylori in dyspeptic subjects. Am J Gastroenterol 1996;91: 1773-7.

20. Sonnenberg A, Schwartz JS, Cutler AF, et al. Cost savings in duodenal ulcer therapy through Helicobacter pylori eradication compared with conventional therapies: Results of a randomized, double-blind, multicenter trial. Gastrointestinal Utilization Trial Study Group. Arch Intern Med 1998; 158:852-60.

21. Unge P, Jonsson B, Stalhammar NO. The cost effectiveness of Helicobacter pylori eradication versus maintenance and episodic treatment in duodenal ulcer patients in Sweden. Pharmacoeconomics 1995;8:410-27.

22. Vakil N, Fennerty MB. Cost-effectiveness of treatment regimens for the eradication of Helicobacter pylori in duodenal ulcer. Am J Gastroenterol 1996;91:239-45.

23. Vakil N, Fennerty B. The economics of eradicating Helico- bacter pylori infection in duodenal ulcer disease. Am J Med 1996;100:60-4S.

24. Weinstein MC, Siegel JE, Gold MR, et al. Recommendations of the Panel on Cost-effectiveness in Health and Medicine. JAMA 1996;276:1253-8.

25. Siegel JE, Weinstein MC, Russell LB, et al. Recommendations for reporting cost-effectiveness analyses. Panel on Cost-Effectiveness in Health and Medicine. JAMA 1996;276:1339-41.

26. Russell LB, Gold MR, Siegel JE, et al. The role of costeffectiveness analysis in health and medicine. Panel on CostEffectiveness in Health and Medicine. JAMA 1996;276: 1172-7.

27. Torrance GW. Social preferences for health states: An empirical evaluation of three measurement techniques. Socioecon Plann Sci 1976;10:129-36.

28. Clarke AE, Goldstein MK, Michelson D, et al. The effect of assessment method and respondent population on utilities elicited for Gaucher disease. Qual Life Res 1997;6:169-84.

29. Johannesson M. Theory, and methods of economic evaluation of health care. Boston: Kluwer, 1996.

30. Sonnenberg A, Everhart JE. Health impact of peptic ulcer in the United States. Am J Gastroenterol 1997;92:614-20.

31. Health, United States, 1998. Hyattsville, MD: Centers for Disease Control and Prevention, National Center for Health Statistics, 1999.

32. Jibril JA, Redpath A, MacIntyre IMC. Changing pattern of admission and operation for duodenal ulcer in Scotland. Br J Surg 1994;81:87-9.

33. Petersen H, Kristensen P, Johannessen $\mathrm{T}$, et al. The natural course of peptic ulcer disease and its predictors. Scand J Gastroenterol 1995;30:17-24.

34. Heaney A, Collins JS, Watson RG, et al. A prospective randomised trial of a "test and treat" policy versus endoscopy based management in young Helicobacter pylori positive patients with ulcer-like dyspepsia, referred to a hospital clinic. Gut 1999;45:186-90.

35. Talley NJ, Janssens J, Lauritsen K, et al. Eradication of Helicobacter pylori in functional dyspepsia: Randomised double blind placebo controlled trial with 12 months' follow up. The Optimal Regimen Cures Helicobacter Induced Dyspepsia (ORCHID) Study Group. Br Med J 1999;318:833-7.

36. McColl K, Murray L, El-Omar E, et al. Symptomatic benefit from eradicating Helicobacter pylori infection in patients with nonulcer dyspepsia. N Engl J Med 1998;339:1869-74.

37. Blum AL, Talley NJ, O'Morain C, et al. Lack of effect of treating Helicobacter pylori infection in patients with nonulcer dyspepsia. Omeprazole plus Clarithromycin and Amoxicillin Effect One Year after Treatment (OCAY) Study Group. N Engl J Med 1998;339:1875-81.

38. Archimandritis A, Balatsos V, Delis V, et al. "Reappearance" of Helicobacter pylori after eradication: Implications on duodenal ulcer recurrence: A prospective 6 year study. J Clin Gastroenterol 1999;28:345-7.

39. Ciociola AA, McSorley DJ, Turner K, et al. Helicobacter pylori infection rates in duodenal ulcer patients in the United States may be lower than previously estimated. Am J Gastroenterol 1999;94:1834-40.

40. Gisbert JP, Pajares JM, Garcia-Valriberas R, et al. Recurrence of Helicobacter pylori infection after eradication. Incidence and variables influencing it. Scand J Gastroenterol 1998;33: 1144-51.

41. Stone MA, Barnett DB, Mayberry JF. Lack of correlation between self-reported symptoms of dyspepsia and infection with Helicobacter pylori, in a general population sample. Eur J Gastroenterol Hepatol 1998;10:301-4.

42. Boutet R. Management of dyspepsia in primary care. GPs are 
already choosing eradication therapy over endoscopy. $\mathrm{Br}$ Med J 1998;316:1388 (letter).

43. Howden CW, Hunt RH. Guidelines for the management of Helicobacter pylori infection. Ad Hoc Committee on Practice Parameters of the American College of Gastroenterology. Am J Gastroenterol 1998;93:2330-8.

44. Moayyedi P. What is the optimum strategy for managing dyspepsia? J Gastroenterol 1998;33(suppl 10):44-7.

45. Parry JM, Foy RC, Woodman CB. How might general practitioner knowledge of patient Helicobacter pylori status change the management of dyspepsia in primary care? J Public Health Med 1998;20:133-6.

46. US Census Bureau. Census, California Congressional District Data. Available from the U.S. Census Bureau via the Internet (http://www.census.gov). Accessed 29 Jul 1999.

47. Laupacis A, Feeny D, Detsky AS, et al. How attractive does a new technology have to be to warrant adoption and utilization? Tentative guidelines for using clinical and economic evaluations. Can Med Assoc J 1992;146:473-81.

48. Revicki DA, Wood M, Wiklund I, et al. Reliability and validity of the Gastrointestinal Symptom Rating Scale in patients with gastroesophageal reflux disease. Qual Life Res 1998;7:75-83.

49. Revicki DA, Wood M, Maton PN, et al. The impact of gastroesophageal reflux disease on health-related quality of life. Am J Med 1998;104:252-8.

50. Velanovich V, Vallance SR, Gusz JR, et al. Quality of life scale for gastroesophageal reflux disease. J Am Coll Surg 1996;183:217-24.

51. Blumenschein K, Johannesson M. Relationship between quality of life instruments, health state utilities, and willingness to pay in patients with asthma. Ann Allergy Asthma Immunol 1998;80:189-94.

52. Bult JR, Hunink MG, Tsevat J, et al. Heterogeneity in the relationship between the time tradeoff and Short Form-36 for HIV-infected and primary care patients. Med Care 1998;36: 523-32.

53. Chancellor JV, Coyle D, Drummond MF. Constructing health state preference values from descriptive quality of life outcomes: Mission impossible? Qual Life Res 1997;6:159-68.

54. Fryback DG, Lawrence WF, Martin PA, et al. Predicting quality of well-being scores from the SF-36: Results from the Beaver Dam Health Outcomes Study. Med Decis Making 1997;17:1-9.

55. Graham DY, Lew GM, Klein PD, et al. Effect of treatment of Helicobacter pylori infection on the long-term recurrence of gastric or duodenal ulcer. A randomized, controlled study. Ann Intern Med 1992;116:705-8.
56. Hentschel E, Brandstatter G, Dragosics B, et al. Effect of ranitidine and amoxicillin plus metronidazole on the eradication of Helicobacter pylori and the recurrence of duodenal ulcer. N Engl J Med 1993;328:308-12.

57. Talley NJ, Vakil N, Ballard ED II, et al. Absence of benefit of eradicating Helicobacter pylori in patients with nonulcer dyspepsia. N Engl J Med 1999;341:1106-11.

58. McColl K, Murray L, El-Omar E, et al. Symptomatic benefit from eradicating Helicobacter pylori infection in patients with nonulcer dyspepsia. N Engl J Med 1998;339:1869-74.

59. Danesh J, Lawrence M, Murphy M, et al. Systematic review of the epidemiological evidence on Helicobacter pylori infection and nonulcer or uninvestigated dyspepsia. Arch Intern Med 2000;160:1192-8.

60. Gold MR, Siegel JE, Russell LB, et al., eds. Cost-effectiveness in health and medicine. New York: Oxford University Press, 1996:82-134.

61. OANDA Currency converter. Olson, and Associates. Available via the Internet (http://www.oanda.com). Accessed 15 Jul 1999.

62. Hamel MB, Phillips RS, Davis RB, et al. Outcomes and cost-effectiveness of initiating dialysis and continuing aggressive care in seriously ill hospitalized adults. SUPPORT Investigators. Study to Understand Prognoses and Preferences for Outcomes and Risks of Treatments. Ann Intern Med 1997; 127:195-202

63. Provenzale D, Schmitt C, Wong JB. Barrett's esophagus: A new look at surveillance based on emerging estimates of cancer risk. Am J Gastroenterol 1999;94:2043-53.

64. Lee SJ, Anasetti C, Kuntz KM, et al. The costs and costeffectiveness of unrelated donor bone marrow transplantation for chronic phase chronic myelogenous leukemia. Blood 1998; 92:4047-52.

65. Gerson LB, Robbins AS, Garber A, et al. A cost-effectiveness analysis of prescribing strategies in the management of gastroesophageal reflux disease. Am J Gastroenterol 2000;95: 395-407.

66. Lieu TA, Gurley RJ, Lundstrom RJ, et al. Projected costeffectiveness of primary angioplasty for acute myocardial infarction. J Am Coll Cardiol 1997;30:1741-50.

67. Chang RW, Pellisier JM, Hazen GB. A cost-effectiveness analysis of total hip arthroplasty for osteoarthritis of the hip. JAMA 1996;275:858-65.

68. Younossi ZM, Singer ME, McHutchison JG, et al. Cost effectiveness of interferon alpha2b combined with ribavirin for the treatment of chronic hepatitis C. Hepatology 1999;30: $1318-24$ 


\section{APPENDIX. HEALTH STATE DESCRIPTIONS}

\section{Perfect Health}

- No abdominal symptoms

- No need for medications

- No need for avoiding certain foods/drinks

- No sleep distrubances from abdominal symptoms

- No anxiety about gastrointestinal disease

\section{Mild Symptoms}

- Abdominal symptoms 2-3 times a week or less

- Symptoms resolve quickly by taking medication

- Do not have to avoid specific drinks or foods

- Rarely wake up during the night

- Rarely feel anxious

\section{Moderate Symptoms}

- Abdominal symptoms about once a day

- Not always resolved by medication

- May have to avoid drinks with caffeine, alcohol, aspirin, and/or other pain relievers

- Wake up during the night about once a week

- Often feel anxious

\section{Severe Symptoms}

- Have abdominal symptoms more than once a day

- Take medication daily

- Consistently have to avoid specific drinks, foods, and/or medications

- Wake up during the night at least 2-3 time a week

- Almost always feel anxious

\section{Adverse Effects of Omeprazole/ Amoxicillin/Clarithromycin}

- Mild nausea or diarrhea for 10 days

- Headache

- Funny taste in mouth

- Abdominal pain

\section{Gastrointestinal Bleeding}

- Vomiting blood prompts emergency room visit

- Blood transfusion and endoscopy performed*

- Two days in intensive care unit

- Nasogastric tube for 2 days*

- Three days in regular hospital bed with restricted diet

- Daily medication for at least 2 months

\section{Obstruction-No Operation}

- Problems with eating for a few weeks, causing nausea, vomiting, pain, and bloating

- Endoscopy*

- Nasogastric tube for 2 days*

- Three days in regular hospital bed with restricted diet

- Daily medication for at least 2 months

\section{Obstruction-With Operation}

- Problems with eating for a few weeks; nausea, vomiting, pain, and bloating

- Endoscopy*

- Major operation on stomach; postoperative pain afterward*

- Nasogastric tube for 7 days*

- Seven days in regular hospital bed with restricted diet

- Daily medication for at least 2 months

\section{Perforation}

- Sudden, severe abdominal pain, nausea, bloating prompts emergency room visit

- Major operation on stomach; postoperative pain afterward*

- Nasogastric tube for 7 days*

- Seven days in regular hospital bed with restricted diet

- Daily medication for at least 2 months

\section{Adverse Effects of Omeprazole Metronidazole/Clarithromycin}

- Must avoid alcohol for 14 days

- Moderate nausea

- Abdominal pain

- Funny taste in mouth

*Endoscopy, blood transfusion, nasogastric tube, and surgery were explained in extended detail. 